\title{
Determining whether catch per unit effort is a suitable proxy for relative crab abundance
}

\author{
L. G. Murray ${ }^{1,2, *}$, R. Seed ${ }^{1}$ \\ ${ }^{1}$ School of Ocean Sciences, College of Natural Sciences, Bangor University, Askew Street, Menai Bridge, LL59 5AB, UK \\ ${ }^{2}$ Present address: Department of Agriculture, Fisheries and Forestry, Rose House, 51-59 Circular Road, Douglas, \\ Isle of Man, IM1 1AZ, British Isles
}

\begin{abstract}
Stock assessments of crabs commonly rely on catch per unit effort (CPUE) data derived from catches in baited traps. Baited traps have been used for many years to estimate the relative abundance of predators in the marine environment. However, traps may result in biased estimates due to inter- and intra-species variations in physiology and behaviour. The aim of this study was to determine the suitability of CPUE as a proxy for the relative abundance of Carcinus maenas. Crab abundance estimates were obtained using underwater camera surveys. The study was conducted on commercial mussel beds in the Menai Strait, United Kingdom. CPUE data were obtained from the local C. maenas fishery operating over the mussel beds. The influence of temperature-dependent feeding rates on CPUE was predicted from the number of mussels consumed at different experimental temperatures in laboratory aquaria. Both CPUE and estimated abundance showed marked seasonal variation. Abundance maxima preceded temperature maxima by 2 mo. CPUE increased with temperature up to $15^{\circ} \mathrm{C}$, while relative crab abundance based on visual surveys exhibited a strong positive correlation with day-length. CPUE appears not to be a suitable proxy for the relative abundance of $C$. maenas because of the effects of temperature on crab activity levels and thus catches.
\end{abstract}

KEY WORDS: Carcinus maenas $\cdot$ Day-length $\cdot$ Feeding $\cdot$ Fisheries $\cdot$ Migration $\cdot$ Photoperiod $\cdot$ Mytilus edulis

Resale or republication not permitted without written consent of the publisher

\section{INTRODUCTION}

Accurate stock assessments of shellfish stocks are essential in order to identify over-fishing or to recommend appropriate levels of exploitation. Fisheries catch per unit effort (CPUE) data form the basis of stock assessments for many commercially important crustacean species. CPUE can provide useful information on population movement and activity and may parallel abundance. However, CPUE is not always a reliable indicator of relative abundance (Maunder et al. 2006). This study assesses the suitability of CPUE as an abundance index of the shore crab Carcinus maenas.

Carcinus maenas has a wide geographic distribution and is often highly abundant. These characteristics make shore crabs a useful model species with which to examine the effectiveness of CPUE as a proxy for rela- tive crab abundance. Shore crabs inhabit a diverse range of environments, including rocky shores, sand and mud flats (Jensen et al. 2002, Rewitz et al. 2004) and mussel beds (Seed \& Suchanek 1992). C. maenas gather at mating 'hotspots' in the intertidal zone shortly before females moult (van der Meeren 1994), which generally occurs during the summer months (Naylor 1962, Styrishave \& Andersen 2000). Following copulation, embryo development takes several months (Naylor 1962). Shore crabs are generally absent from the intertidal zone during winter (Crothers 1968, Gascoigne et al. 2005). Although less commercially important than many other crustaceans, C. maenas is of particular concern as an invasive species in North America (Rossong et al. 2006, Lynch \& Rochette 2009) and as a predator of molluscs (Miron et al. 2005) in both Europe and North America. 
Several methods have been used previously to assess the relative abundance of Carcinus maenas, including traps with bait (Rewitz et al. 2004) and without bait (Hunter \& Naylor 1993, Gascoigne et al. 2005). The effectiveness of baited trap catches as a proxy for relative abundance is dependent on the influence of factors such as feeding rates and reproductive condition, which may vary both temporally and spatially and thus affect the catchability of the species. Baited traps can be both size and sex biased (Williams \& Hill 1982, Addison \& Lovewell 1991). Population size does undoubtedly influence catches (Maceina et al. 1993, Wright et al. 2006, Walter et al. 2007). However, it is important that the effects of physiological and behavioural factors on baited trap CPUE are understood if these values are to be used to estimate changes in crab stock size.

Migration of crabs has a major impact on the intraannual trends in abundance. Annual offshore migrations are undertaken by many crustacean species, including Macropipus holsatus (Venema \& Creutzberg 1973), Cancer pagurus (Ungfors et al. 2007) and Carcinus maenas. Welch (1968) suggested that increases and decreases in C. maenas abundance are associated with rising and falling temperature. The estimates used by Welch (1968) were based on baited trap catches and the observations of fishers. There is no doubt that unusually low winter temperatures can result in mass mortality of $C$. maenas and other species (Crisp 1964). Thus, there is a clear advantage in $C$. maenas migrating to deeper, warmer water during the winter. Crisp (1964) reiterates the suggestion of Naylor (1963) that annual migrations by C. maenas occur in response to changing temperature, and this hypothesis is supported by Welch (1968). Atkinson \& Parsons (1973) observed that annual migrations by C. maenas occurred around $8^{\circ} \mathrm{C}$; below this temperature more crabs were observed in the subtidal zone. Atkinson \& Parsons (1973), like Welch (1968), estimated abundance using baited traps. Therefore, although there appears to have been a general consensus that the annual migrations of $C$. maenas occur in response to temperature, the only studies that support this hypothesis are based upon relative abundance estimates derived from catches in baited traps. Consequently, there is a need to examine changes in CPUE relative to other abundance indices.

A commercial Carcinus maenas fishery operates in the Menai Strait, which from 2006 onwards has recorded the weight of $C$. maenas caught per day and the effort expended, as the number of traps hauled. It has been compulsory since January 2006 for UK fishing vessels $<10 \mathrm{~m}$ to submit landings and effort data under licensing requirements, but it is essential that these data be validated before they are used in assess- ments of crustacean stocks. The aim of this study was to determine whether CPUE is a suitable proxy for the relative abundance of $C$. maenas. It was hypothesised that, due to the effects of temperature on crab activity levels and feeding rates, CPUE would not vary proportionally with relative abundance.

\section{MATERIALS AND METHODS}

Camera- and dredge-based surveys. Data on total catches and CPUE from the commercial crab fishery in the Menai Strait were compared to abundance measurements and feeding rates. Crab abundance was estimated from underwater visual surveys conducted on the commercial mussel beds. Although it is unlikely that visual surveys provide a perfect measure of abundance, it is assumed in the present study that visual surveys provide a closer measure of absolute abundance than baited trap-based CPUE, as they are not subject to the direct effects of temperature and feeding rates. Henceforth, the term 'abundance' will refer to the spatial density of crabs as measured in the visual surveys.

An RV-Marine underwater camera was attached to a steel frame at a height of $55 \mathrm{~cm}$, giving a $0.25 \mathrm{~m}^{2}$ field of view when on the seabed. The images were recorded via an Audio/Video (A/V) cable to mini Digital Video (DV) tape using a Canon MV850i camcorder. The camera was lowered and lifted at intervals along transects of $\sim 100 \mathrm{~m}$ at each of 9 sites distributed across commercial mussel lays in the subtidal and intertidal zones, and in adjacent areas without mussels (Fig. 1). The camera was left on the seabed for around $5 \mathrm{~s}$ before being lifted and lowered while the vessel drifted. Surveys were undertaken in the $2 \mathrm{~h}$ before high water, approximately monthly from March 2006 to September 2007. Twenty images were extracted at random from the video of each transect using Video2Photo software. Images were analysed using Image $\mathrm{J}$; all crabs were counted and measured. During the winter months, from November to February, when Carcinus maenas was absent from the intertidal zone and visibility in the subtidal zone was poor, samples of crabs were collected from mussel beds by commercial mussel dredgers. Start and finish points of tows $(\sim 1000 \mathrm{~m})$ were recorded using a GPS receiver. Dredges were emptied into hoppers before mussels and crabs were passed up a conveyor belt where all visible crabs were removed, counted and measured. At least 6 trawls were conducted each month from January to March 2006, and from October 2006 to March 2007. All crabs were counted and carapace width (CW) measured, and sex and colour morph were recorded. During October, abundance as measured by dredging was compared with abundance measured using the video system. 
Fig. 1. Video sampling sites in the Menai Strait. Shaded areas indicate the bounds of sampling areas within intertidal and subtidal mussel lays and areas without mussels. Dashed line indicates boundary between intertidal and subtidal zones

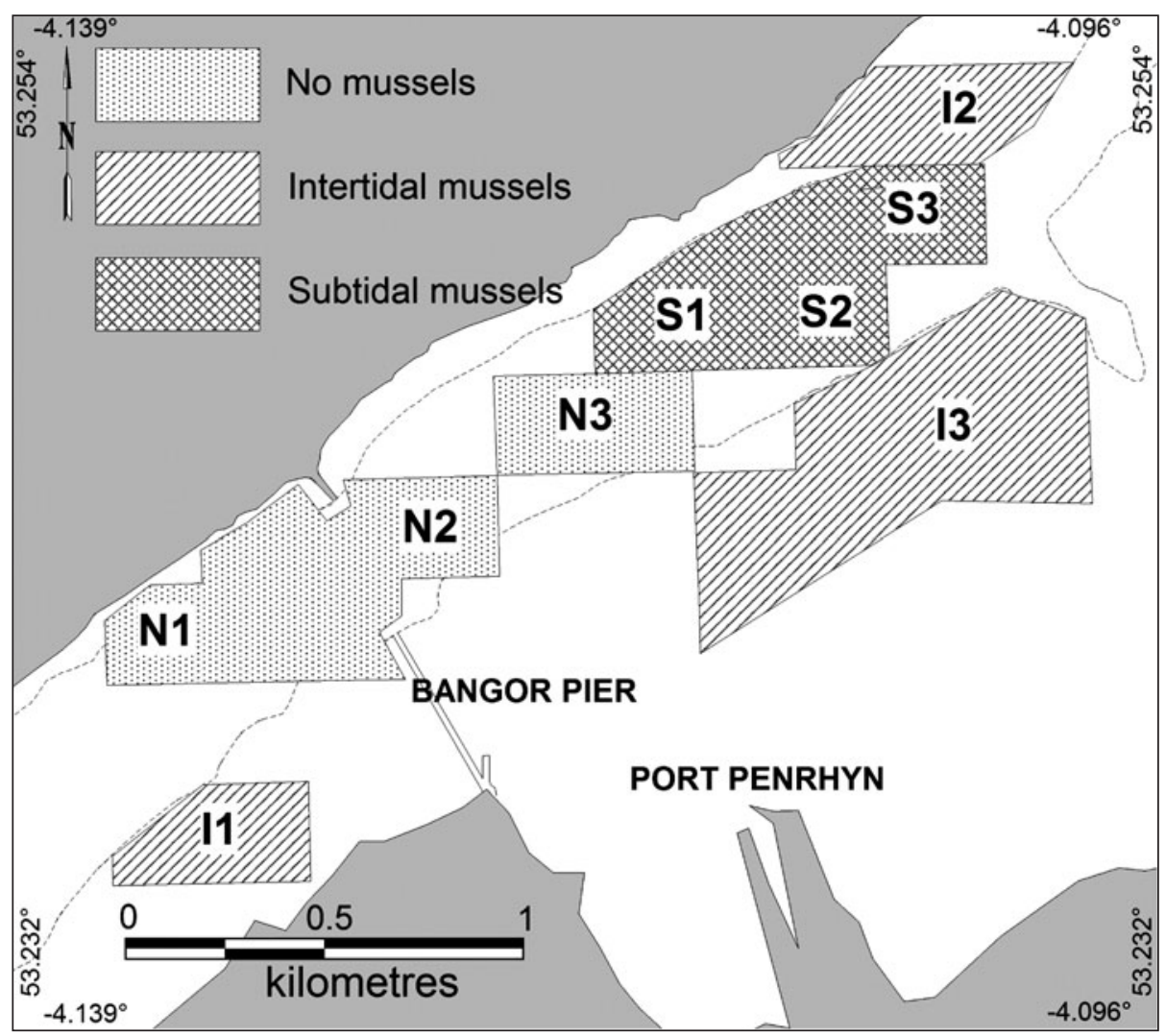

Temperature. Seawater temperature in the Menai Strait was recorded during the study period at the low water mark using a Valeport 600 DR Mk III CTD (Valeport) or Tinytag Plus 2 temperature logger (Gemini Data Loggers) $\sim 3 \mathrm{~km}$ southwest of the study site. The Menai Strait is strongly tidal and well-mixed with a residual flow to the southwest (Tweddle et al. 2005); thus, temperature is unlikely to vary substantially over the study site or between the temperature logger location and the study site.

Catch per unit effort. CPUE data were obtained from the commercial Carcinus maenas fishery operating over the mussel beds in the Menai Strait. This fishery is prosecuted by a single vessel, employed by mussel fishermen largely as a means of reducing crab predation on the commercial mussel beds. The number of traps hauled $\mathrm{d}^{-1}$ ranged from 118 to 330, with a mean of $231 \pm 31$ hauled $\mathrm{d}^{-1}$. The weights of catches were estimated from the number of bags of crabs landed each day, each bag weighing approximately $30 \mathrm{~kg}$. Effort was recorded as the number of traps hauled. Traps were baited with dab Limanda limanda, usually with half a fish. CPUE was calculated in terms of the weight of the catch per trap; the number of crabs was then estimated, on the basis of the mean $\mathrm{CW}$ of $C$. maenas observed over the mussel beds during the survey period, using the relationship between CW and total wet weight, $y=0.0003 x^{2.912}$, where $x=$ carapace width, and $y=$ weight (Murray 2008). A sub-sample of around 200 crabs was collected from commercial traps once each month from May to September 2007, all of which were measured, and sex and colour morph were recorded.

Feeding rates. To assess the effect of temperature on feeding rates, undamaged male Carcinus maenas with CWs ranging from 60 to $70 \mathrm{~mm}$ were collected from the mussel beds in the Menai Strait by dredging or with baited traps. Crabs were kept in aquaria with running seawater and were fed to satiation on mussel flesh. Food was then withheld for $48 \mathrm{~h}$ to standardize hunger levels before feeding trials began (Elner \& Hughes 1978, Jubb et al. 1983) and to allow crabs to acclimatize. Feeding rates were determined at $6,8,10,13,16$ and $18^{\circ} \mathrm{C}$. Crabs were kept individually, and each crab was presented with 35 mussels ranging in length from 20 to $30 \mathrm{~mm}$. The number of mussels consumed was recorded after $24 \mathrm{~h}$. Three crabs were fed at each temperature. The weight of flesh consumed was estimated from the relationship between mussel length and dry flesh weight (DFW). All mussels were measured to $0.1 \mathrm{~mm}$ with dial calipers. Flesh was removed from 35 mussels and dried at $60^{\circ} \mathrm{C}$ for $48 \mathrm{~h}$ or until a constant weight was reached. 
Statistical analyses. Factor analysis using principal components was used to examine the distribution of CPUE, abundance, day-length, temperature and feeding rate data. Day-length data were obtained from the US Naval Observatory (USNO 2007) and modelled using a sine wave function. Sine wave models were also used to estimate daily temperature and abundance. Daily feeding rates were then estimated from the relationship between temperature and feeding rates observed in aquaria. All regression analyses were conducted using SigmaPlot (Systat Software). Factor analysis was conducted using Minitab.

\section{RESULTS}

There was a significant quadratic relationship $\left(\mathrm{R}^{2}=\right.$ $\left.0.9984, F_{2,3}=927.3559, \mathrm{p}<0.0001\right)$ between temperature and the DFW of mussels consumed $(\mathrm{C}=-2.7185+$ $0.6579 \mathrm{~T}-0.0252 \mathrm{~T}^{2}$, where $\mathrm{C}=\mathrm{DFW}$ consumed and $\mathrm{T}=$ temperature; Fig. 2). Feeding rates were greatest at $13^{\circ} \mathrm{C}$, declining sharply at lower temperatures and also decreasing slightly at higher temperatures.

CPUE ranged from $<1 \mathrm{~kg}$ trap ${ }^{-1}$ to $9.6 \mathrm{~kg} \mathrm{trap}^{-1}$ when soak time was $1 \mathrm{~d}$ (Fig. 3a). Longer soak times, $>4 \mathrm{~d}$, were restricted to the winter months, when traps were hauled less often due to smaller catches (Fig. 3b). CPUE was up to $7.7 \mathrm{~kg} \mathrm{trap}^{-1}$ when soak time was up to $3 \mathrm{~d}$, or $4 \mathrm{~kg}$ with a soak time of $4 \mathrm{~d}$. CPUE of Carcinus maenas increased during the summer months before declining from September 2006 to January 2007, closely following changes in temperature (Fig. 4). Maximum CPUE was recorded during September 2006 ( Day 258, measured from 01/01/2006), and the minimum during March 2006 ( Day 75) and 2007 ( Day 410). Seawater temperature ranged from $5^{\circ} \mathrm{C}$ in March 2006 to $17^{\circ} \mathrm{C}$ in July 2006 (Fig. 4). Both temperature and CPUE were described using a 4 parameter sine wave model, $y=$ $y_{0}+a \cdot \sin (2 \pi x / b+c)$. Parameter $b$ is the frequency and should be close to $365 \mathrm{~d}$, as temperature and crab CPUE follow an annual cycle. Parameter $a$ is the amplitude, or magnitude of oscillation about the mean value of temperature or CPUE, while $y_{0}$ is the displacement, and thus the mean CPUE or mean temperature. Parameter $C$ accounts for the differences in timing of the maximum and minimum CPUE or temperature between years and thus must be adjusted between any 2 years; $\mathrm{x}$ is time (days). Parameter values for the CPUE model are: $y_{0}=99.8588, a=$ 54.6336, $b=356.9958$, and $c=3.8275\left(F_{3,11}=\right.$ $\left.10.318, p=0.0016, R^{2}=0.738\right)$. Over longer time scales the sine wave model is only suitable

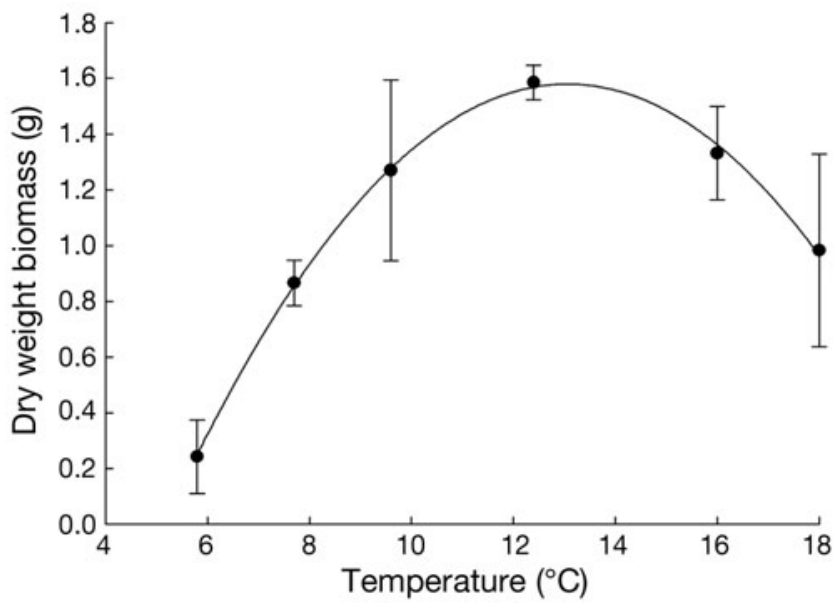

Fig. 2. Carcinus maenas. Dry weight of flesh consumed by a total of 18 individuals kept at 6 temperatures in laboratory aquaria

where CPUE, temperature or abundance maxima and minima remain consistent between years. Nevertheless, over the duration of this study, the model is useful in quantifying the seasonal oscillation in CPUE, temperature and abundance and is not intended to be extrapolative.

There was a significant quadratic correlation between temperature and CPUE $\left(y=-0.9892 \mathrm{~T}^{2}+32.1 \mathrm{~T}-122.7\right.$,
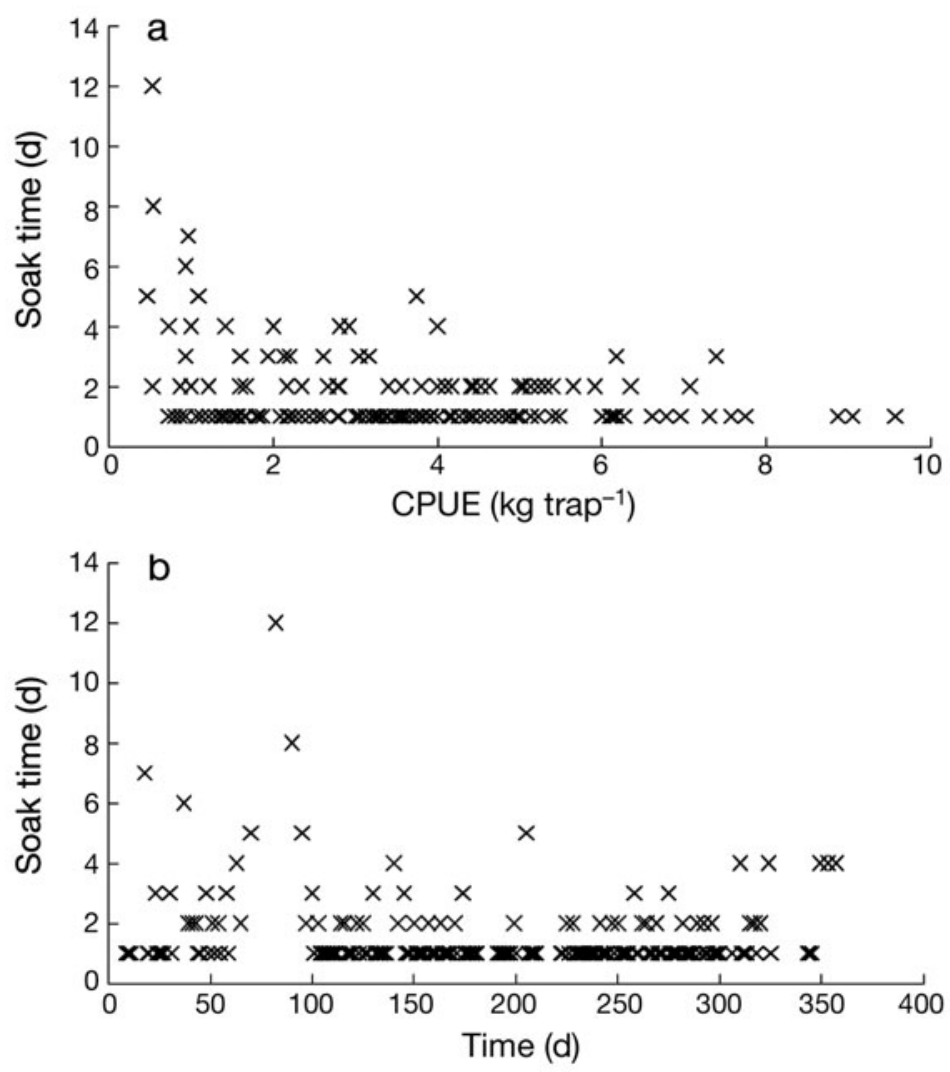

Fig. 3. Carcinus maenas. Variation in soak time with (a) CPUE and (b) time from 1 January 2006 


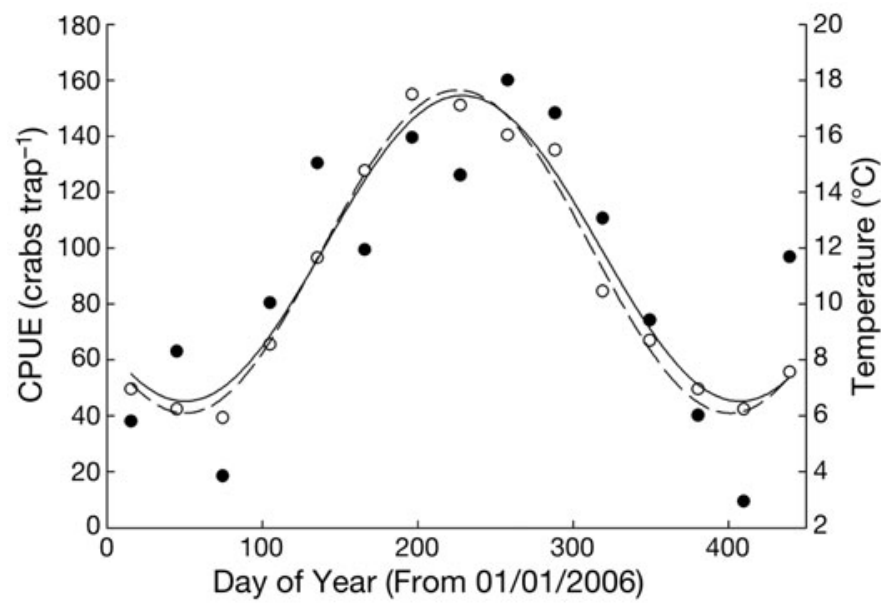

Fig. 4. Carcinus maenas. CPUE (•) and sine wave regression line (solid line) and mean monthly seawater temperature $(0)$ with regression line (dashed line) in the Menai Strait

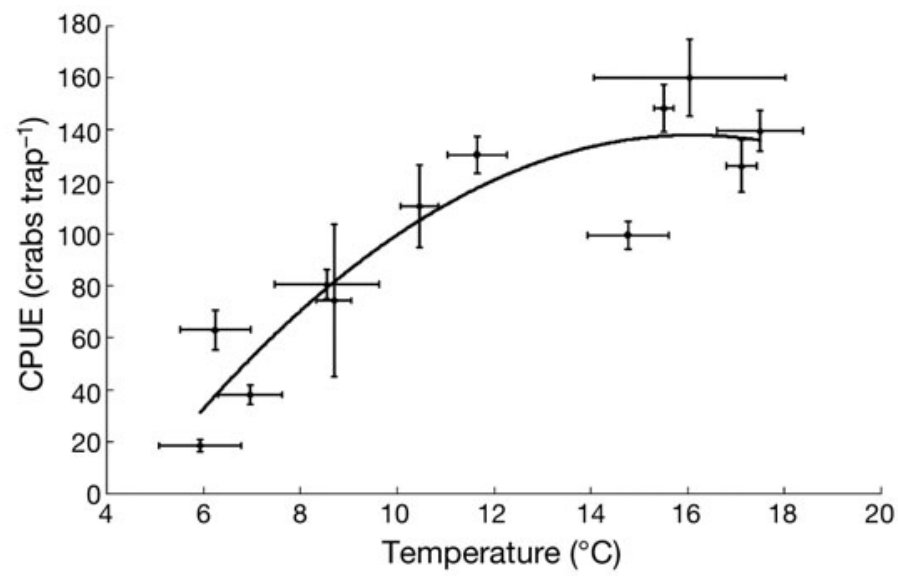

Fig. 5. Carcinus maenas. Quadratic relationship between temperature and CPUE. Error bars indicate $\pm 1 \mathrm{SE}$ for CPUE and $\pm 1 \mathrm{SD}$ for temperature

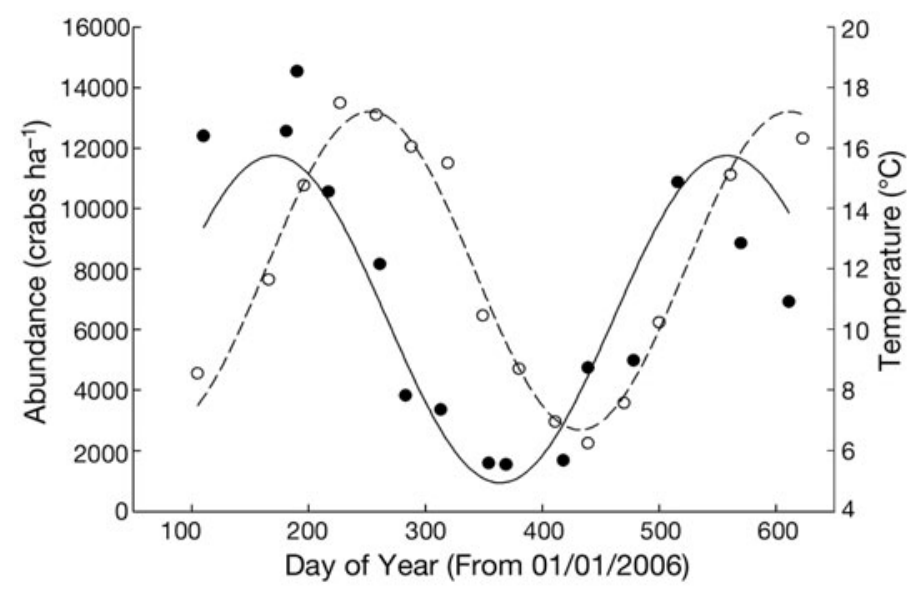

Fig. 6. Carcinus maenas. Abundance ( $/$ /solid line) and temperature (O/dashed line) in the Menai Strait with sine wave models fitted to data spanning 18 mo. Abundance estimates were based on video footage and, during winter (November to February), dredged samples. Abundance estimates from the dredges were increased by a factor of 1.5 due to undersampling relative to the visual surveys
$F_{2,9}=26.14, \mathrm{p}<0.001, \mathrm{R}^{2}=0.853 ;$ Fig. 5); residual variances were equal ( $\mathrm{p}=0.921)$, and residuals were normally distributed (Kolmogorov-Smirnov statistic, K-S = 0.115, p=0.995). CPUE did not peak until September (Fig. 4) despite the peak in abundance estimated from the video footage shot in July (Fig. 6). It was also during July that seed mussels, and associated crabs, were imported to the Menai Strait as part of the annual management cycle of the mussel fishery.

Both temperature and crab abundance exhibited pronounced annual maxima and minima (Fig. 6). The relationship between time and temperature is also best described by a 4 parameter sine wave function; where, $y_{0}=11.9461, a=5.2611, b=$ 359.0206, and $c=3.4342\left(\mathrm{R}^{2}=0.973, F_{3,11}=\right.$ 133.184, $\mathrm{p}<0.0001)$. The coefficients relating time and abundance are: $y_{0}=6346.6918, a=5403.6519$, $b=387.4755$, and $c=-1.1890\left(\mathrm{R}^{2}=0.8154, F_{3,11}=\right.$ 16.201, $\mathrm{p}=0.0002)$. The peak abundance occurred earlier in 2007 than in 2006, while the maximum temperature occurred slightly later in 2007 than in 2006. The rate of change in abundance parallels the rate of change in temperature 2 mo later. The mean number $( \pm 1 \mathrm{SE})$ of crabs as estimated by dredging $(\mathrm{n}=6)$ was $0.19 \pm 0.04 \mathrm{crabs} \mathrm{m}^{-2}$ in October 2006, falling to $0.1 \pm 0.01 \mathrm{crabs} \mathrm{m}^{-2}$ in November. The mean number of crabs recorded in video surveys in October was higher, ranging from $0.34 \pm 0.14 \mathrm{crabs} \mathrm{m}^{-2}$ to $0.25 \pm 0.12 \mathrm{crabs} \mathrm{m}^{-2}, 1 \mathrm{wk}$ before and 1 wk after dredge sampling, respectively. Therefore, it was estimated that dredging underestimated crab abundance by $33 \%$ relative to video surveys, and abundance estimates were increased by a factor of 1.5 accordingly. Prior to the decline in abundance observed in the dredge survey, both intertidal and subtidal video surveys showed a sharp decline in abundance between September and October, and no crabs were found intertidally in video surveys during the winter months despite good visibility.

Mean monthly seawater temperature and Carcinus maenas abundance were not significantly correlated (Fig. $7 \mathrm{a} ; y=467.1 \mathrm{~T}+438, \mathrm{R}^{2}=0.229, F_{1,11}=$ $3.2635, \mathrm{p}=0.098)$. However, there was a significant linear correlation between temperature and the abundance measured 1 mo earlier (Fig. 7b; $y=874.6 \mathrm{~T}+4222.2, \mathrm{R}^{2}=0.679, F_{1,11}=23.305$, $\mathrm{p}=0.0005)$. This correlation was even stronger between temperature and the abundance measured 2 mo earlier (Fig. $7 \mathrm{C} ; 1018.6 \mathrm{~T}+5748.5, \mathrm{R}^{2}=$ $\left.0.828, F_{1,11}=53.101, \mathrm{p}<0.0001\right)$. Residual variance was equal for all regressions ( $p>0.583)$, and residuals were normally distributed $(\mathrm{K}-\mathrm{S}<0.173, \mathrm{p}>$ $0.722)$. 

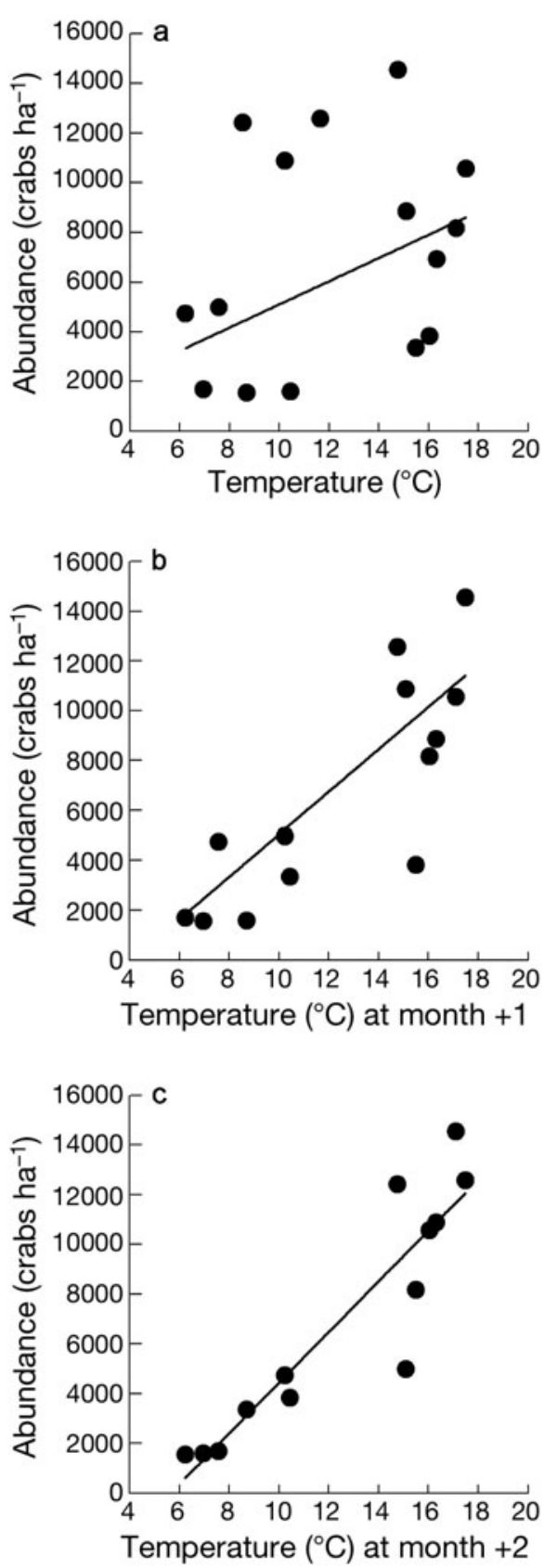

Fig. 7. Carcinus maenas. Relationships between abundance and (a) temperatures within the same month, (b) temperatures 1 mo after abundance was measured, and (c) temperatures 2 mo after abundance was measured

There was no clear trend in the mean CW of crabs between January 2006 and October 2007. Mean CW ranged from a minimum of $35.0 \pm 12.0 \mathrm{~mm}$ up to a maximum of $51.9 \pm 9.7 \mathrm{~mm}$ across all sampling methods used. The mean $\mathrm{CW}$ of crabs measured in video quadrats ranged from $36.4 \pm 14.4 \mathrm{~mm}$ in June 2006 to $58.3 \pm 7 \mathrm{~mm}$ in May 2007. The percentage of male crabs observed in dredges ranged from 13 to $53 \%$, while the percentage of green colour forms ranged from 21 to $94 \%$ (Table 1). In baited traps the percentage of males ranged from 26 to $46 \%$, and the percentage of green crabs from 19 to $86 \%$.

The first 3 factors calculated using principal components explained $94 \%$ of the variance in the abundance, CPUE, day-length, feeding rate and temperature data (Table 2). Abundance and day-length loaded highly on Factor 1, while CPUE and temperature were the highest loadings on Factor 2 (Fig. 8). Feeding rates, and to a lesser extent temperature, loaded highest on Factor 3. Temperature was the best predictor of CPUE, while day-length showed a very strong correlation with abundance (Table 3). None of the factors was a stronger predictor of CPUE and abundance than temperature and day-length, respectively. Abundance was not significantly correlated with CPUE (Table 3).

\section{DISCUSSION}

In this study we hypothesised that CPUE would be influenced by temperature and feeding rates and thus would not vary proportionally with abundance. The results show that changes in CPUE do broadly reflect the intra-annual changes in abundance of Carcinus maenas but underestimate the magnitude of variability and are offset by 2 mo, succeeding changes in abundance. Although abundance is likely to influence CPUE, the strong association between temperature and CPUE may mask the underlying changes in abundance.

Any method used to estimate the abundance of a highly motile species will be subject to the variability of environmental parameters and the behaviour of the organism under study; sampling subtidal organisms is particularly challenging. One solution to this problem is to use several sampling techniques. However, these different methodologies may, as in this study, appear to produce conflicting results. Neither survey method used is free of artefacts.

Visual surveys may preferentially sample active crabs, which are more visible, and the presence of the camera itself may cause crabs to seek shelter. Furthermore, crabs may not be detected in visual surveys when present in low numbers, and cameras are ineffective in turbid water. In addition, no information is gained about the section of the population sampled, or any sex or colour morph bias. Nevertheless, visibility remained good in the intertidal zone throughout this study, and although visibility was low in the subtidal zone during winter, crab abundance remained relatively low subtidally during this period. Adult crabs were absent from the intertidal zone, or numbers were below the detection limit, from December to February, as was also observed by Hunter \& Naylor (1993) in the Menai Strait 
Table 1. Carcinus maenas. Carapace widths, ratio of males (M) to females (F), and ratio of green $(\mathrm{G})$ to red $(\mathrm{R})$ individuals observed in this and other studies in the United Kingdom. - = no data

\begin{tabular}{|c|c|c|c|c|c|c|c|}
\hline Author & Location & $\begin{array}{c}\text { Carapac } \\
\text { Mean }\end{array}$ & $\begin{array}{l}\text { e wid } \\
\text { Min }\end{array}$ & $\begin{array}{l}\text { th }(\mathrm{mm}) \\
\text { Max }\end{array}$ & $M: F^{N}$ & $\begin{array}{l}\text { Mean } \\
\text { G:R }\end{array}$ & $\begin{array}{l}\text { ratio } \\
\text { Season }\end{array}$ \\
\hline Naylor (1962) & Swansea & 55 & 50 & 63 & 1.3 & _- & Annual \\
\hline Hunter \& Naylor (1993) & Menai Strait & 47 & 39 & 55 & 2.8 & 3.4 & Summer \\
\hline Hunter \& Naylor (1993) & Menai Strait & 42 & 37 & 49 & 5.3 & 8.1 & Winter \\
\hline Rewitz et al. (2004) & Looe Estuary & 50 & 45 & 61 & 0.6 & 3.6 & Summer \\
\hline This study (dredging) & Menai Strait & 43 & 39 & 51 & 0.4 & 0.8 & Winter \\
\hline This study (baited traps) & Menai Strait & 46 & 41 & 49 & 0.7 & 2.5 & Summer \\
\hline This study (video) & Menai Strait & 44 & 39 & 49 & - & - & Annual \\
\hline
\end{tabular}

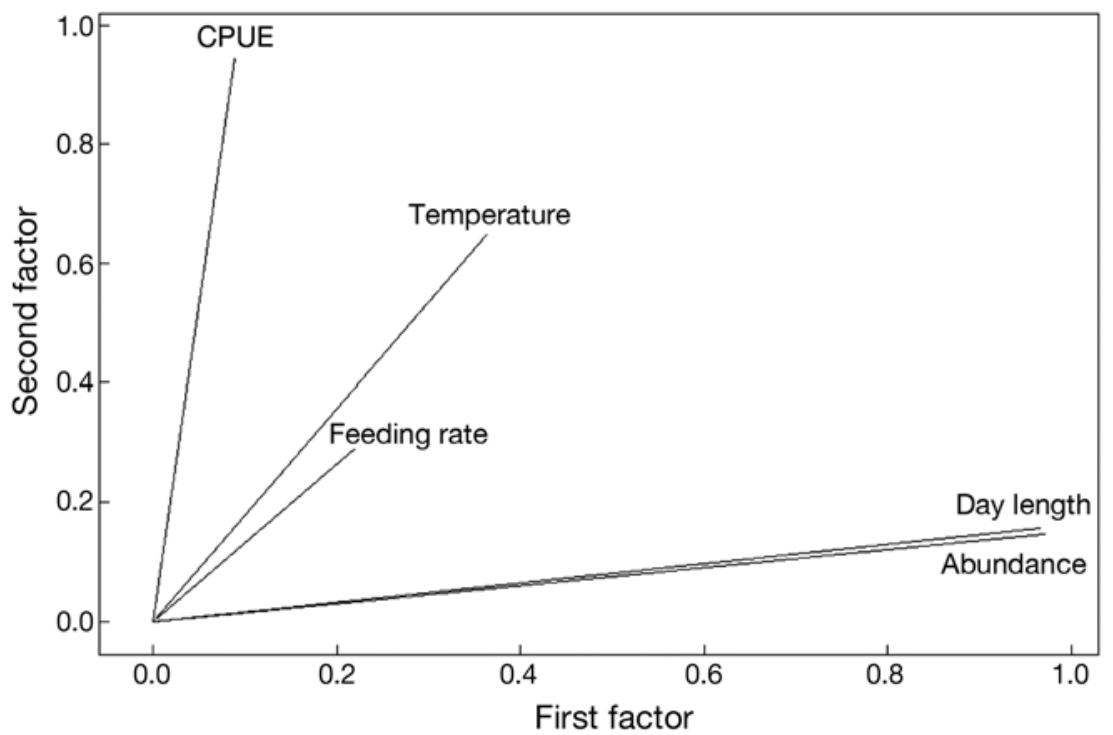

Fig. 8. Carcinus maenas. Factor analysis loadings on Carcinus maenas catch per unit effort (CPUE) and abundance, and modelled day-length, feeding rates and seawater temperature in the Menai Strait

during November. All the survey methods used are likely to underestimate the abundance of juvenile and small crabs, as is evident from the minimum sizes of crabs observed (Table 1). No clear changes in CW were observed during the course of the study. Therefore, the crabs migrating offshore are presumably a representative subsection of the population with $\geq 40 \mathrm{~mm} \mathrm{CW}$.

Table 2. Carcinus maenas. Results of factor analysis using principal components (varimax rotated) of data on catch per unit effort (CPUE) and modelled abundance, day-length, temperature and feeding rates

\begin{tabular}{|lcccc|}
\hline Variable & Factor 1 & Factor 2 & Factor 3 & Communality \\
\hline CPUE & 0.089 & 0.944 & 0.202 & 0.939 \\
Temperature & 0.363 & 0.648 & 0.486 & 0.787 \\
Feeding rate & 0.220 & 0.292 & 0.916 & 0.972 \\
Abundance & 0.970 & 0.146 & 0.180 & 0.996 \\
Day-length & 0.966 & 0.156 & 0.202 & 0.997 \\
\% Variance & 41.2 & 28.8 & 23.8 & 93.8 \\
\hline
\end{tabular}

It has long been recognised that catches using baited traps are dependent not only on abundance but upon the activity of the animal (Crothers 1968), and traps are potentially size and sex biased (Williams \& Hill 1982). The reliability of fisheries-dependent data must also be considered. The Carcinus maenas fishery prosecuted in the Menai Strait exists largely to reduce predation on the mussel beds and is conducted in unison with the mussel fishery. Consequently, the numbers of crabs removed by the crab fishery are of great interest to mussel fishermen. In addition, as the fishery is prosecuted by only a single vessel, the traps, bait and the areas fished are consistent over time. Soak time appears to be influenced by CPUE, rather than soak time affecting CPUE. Although CPUE was low when soak times were longer, low CPUE was also common with soak times of only $1 \mathrm{~d}$.

Seawater temperature in the Menai Strait closely follows air temperature, but the minimum air temperature occurred in February, while seawater was coldest during March. Crabs began moving onshore when water temperatures were at a minimum but when air temperatures were increasing, and the risk of temperature-induced mortality was therefore lessened. No live crabs $>30 \mathrm{~mm}$ were observed on the intertidal mussel beds when tidally exposed, though Carcinus maenas when submerged was regularly observed in video surveys of the intertidal zone (Murray et al. 2007). This is in contrast to rocky shores where C. maenas is common in the exposed intertidal zone, particularly during the spring and summer (Seed 1969). The fact that tidal migration was undertaken by the majority of the adult crab population over the commercial mussel beds in the Menai Strait is almost certainly due to the lack of suitable refuges for larger crabs when exposed to air and the potential of predation by birds.

Temperature is undoubtedly a major influence on the behaviour of Carcinus maenas and crustaceans in general. Tidal and diurnal locomotor rhythms in $C$. maenas can be altered by varying temperature (Naylor 1958, 1963) and temperature also exerts the greatest effect on cardiac activity in C. maenas (Aagaard 
Table 3. Carcinus maenas. Results of regression analysis $(y=a x+b)$ of catch per unit effort (CPUE), day-length, modelled temperature, abundance and feeding rate data, and Factors 1, 2 and 3, ranked according to strength of correlation. Data were reduced to 2 and 3 factors as predictors of CPUE and abundance, respectively. ${ }^{*}=\mathrm{p}<0.05$. The major loadings on factors are indicated in brackets: T: temperature, F: feeding rate, A: Abundance, D: day-length, C: CPUE

\begin{tabular}{|llcccc|}
\hline $\begin{array}{l}\text { Dependent } \\
\text { variable }\end{array}$ & $\begin{array}{l}\text { Independent } \\
\text { variable }\end{array}$ & $a$ & $b$ & $\mathrm{R}^{2}(\%)$ & $F_{1,190}$ \\
\hline CPUE & Temperature & 0.305 & -0.227 & $39.4^{*}$ & 123.29 \\
& Factor 2 (TF) & 1.126 & 3.609 & $38.6^{*}$ & 119.49 \\
& Feeding rate & 2.647 & 0.378 & $27.2^{*}$ & 70.83 \\
& Day-length & 0.173 & 1.355 & $8.2^{*}$ & 16.90 \\
& Abundance & $1.47 \times 10^{-4}$ & 2.502 & $7.6^{*}$ & 15.69 \\
& Factor 1 (AD) & 0.222 & 3.609 & 1.5 & 2.88 \\
Abundance & Day-length & 1138 & -7300 & $99.8^{*}$ & 100493.79 \\
& Factor 2 (DT) & 3279 & 7552 & $92.1^{*}$ & 2220.42 \\
& Temperature & 461.9 & 1735 & $25.5^{*}$ & 64.94 \\
& Feeding rate & 4138 & 2500 & $18.7^{*}$ & 43.66 \\
& Factor 3 (FT) & 609.1 & 7552 & $3.2^{*}$ & 6.24 \\
& Factor 1 (CT) & 426.3 & 7552 & 1.6 & 3.00 \\
\hline
\end{tabular}

1996). Avoidance of extreme temperatures is probably an important reason for the annual migrations of shore crabs, even if temperature does not provide the cue which initiates migration. CPUE varied proportionally with temperature, while the video-based abundance estimates in this study indicate that offshore migration begins before the peak in summer temperature (Fig. 6). Avoidance of high temperatures may be as important as avoidance of low temperatures because of the risks of desiccation, predation from birds and increased energy requirements in response to raised metabolic rate, in which case offshore migration before the temperature maximum is reached would be advantageous.

Response to temperature change may have evolved as those crabs which responded most effectively to temperature changes avoided being exposed to temperature at the extremes of, or beyond, their range of tolerance. However, day-length was strongly correlated with video estimates of abundance in this study and is also a possible cue for crab migration. Many animal species have been shown to respond in various ways to changing photoperiod (Kenagy 1981, Silverin et al. 1993, Gwinner 1996, Watari \& Arai 1997, Last \& Olive 2004), and several studies have shown that crustaceans respond to changing light conditions. Aguzzi et al. (2004) attributed greater catches of the Norway lobster Nephrops norvegicus during spring and summer to higher light intensity, while Aguzzi et al. (2005) suggested that creels should be deployed around sunset to sample, during the peak feeding period, the brackish water shrimp Palaemonetes varians, which exhibits daily feeding rhythmicity. However, further work is necessary to establish whether feeding activity and metabolism are linked to photoperiod or light intensity. Such an association has been observed in Antarctic krill Euphausia superba, in which digestive gland length and respiration rate were significantly higher in groups exposed to $24 \mathrm{~h}$ light, or a lightdark regime, than in those kept in darkness, and feeding activity (clearance rates) was also significantly higher under a $24 \mathrm{~h}$ light regime (Teschke et al. 2007).

Identifying when a predator will not attempt to maximize energy intake may help to elucidate the mechanisms governing predator migration; however, the relationship between metabolism and feeding rates is not straightforward. Elner (1980) and Robertson et al. (2002) found no significant difference in the meal size of Carcinus maenas between high and low temperatures, despite the increase in metabolism at higher temperatures (Wallace 1973, Robertson et al. 2002). SanchezSalazar et al. (1987) observed increasing energy intake by $C$. maenas, feeding on cockles, with increasing temperature, and Wallace (1973) also found that food intake by $C$. maenas increased with temperature. In contrast, Elner (1980) found no significant difference in the feeding rates of $C$. maenas kept at 10 or $17^{\circ} \mathrm{C}$. Therefore, the relationships between temperature and energy intake are unclear. Feeding rates did not show a strong linear relationship with CPUE in the present study; thus, general crab activity levels-including foraging, feeding and tidal migration-may have a greater influence on CPUE than feeding rates alone.

The nature of the relationship between temperature, feeding rates and catches will determine how effective CPUE is as an abundance index. For instance, Aagaard et al. (1995) attributed low spring catches of Carcinus maenas to a rapid increase in temperature to which crabs had not acclimatised, which suggests that CPUE may not always be indicative of abundance. Katsanevakis et al. (2005a) found standard metabolism in Octopus vulgaris to be $37 \%$ higher at $28^{\circ} \mathrm{C}$ than at $20^{\circ} \mathrm{C}$ and suggested that the annual migration of this species into cooler water during the summer may be to lower metabolism and reduce energy requirements (Katsanevakis et al. 2005b). Thus, although crabs may eat more prey with increasing temperature (SanchezSalazar et al. 1987), this increase in food intake may occur only up to a point beyond which crabs will migrate in order to reduce metabolic rate and energy requirements. The risk of mortality in crabs stranded in the intertidal zone is also likely to be much greater during the warmest and coldest months.

The results presented in this study indicate that CPUE may not be a good proxy for crab abundance. However, it is important to consider that in most cases, 
for stock assessment purposes, inter-annual variation of abundance is of more interest than intra-annual variation. Therefore, assuming sampling is undertaken throughout the year, a temporal difference between CPUE and abundance should not be important. However, if regular intra-annual sampling is not conducted, then CPUE may be a poor indicator of abundance. Likewise, if seasonal migration is of interest, then additional sampling techniques should be considered. Given the apparent effects of temperature on CPUE, rising seawater temperature may result in increased CPUE, which could be interpreted, incorrectly, as an increase in abundance. Abundance estimates based solely on CPUE should therefore be viewed with caution, particularly as CPUE and abundance may follow a similar trend, showing an annual rise and fall. It must also be considered that visual surveys do not provide a perfect means of estimating abundance.

Photoperiod and temperature showed the strongest relationships with abundance and CPUE, respectively. Factors derived from time-series data of multiple variables were weaker predictors of CPUE and abundance. Only with the collection of long-term data sets using multiple methods of sampling, combined with studies examining behaviour and physiology, can reliable abundance indices be developed. It is important that further research be conducted to establish whether such differences in abundance indices are also evident in species other than Carcinus maenas and in other geographical areas.

Acknowledgements. This work was funded by a European Social Fund PhD studentship. Thanks to T. Jones (Extramussel) for providing crab CPUE data and for sponsoring the work, D. Bowers for providing temperature data, T. R. Gallagher, G. P. Jones and B. Roberts for assisting with laboratory and field work, and to E. R. Howlett.

\section{LITERATURE CITED}

Aagaard A (1996) In situ variation in heart rate of the shore crab Carcinus maenas in relation to environmental factors and physiological condition. Mar Biol 125:765-772

- Aagaard A, Warman CG, Depledge MH (1995) Tidal and seasonal changes in the temporal and spatial distribution of foraging Carcinus maenas in the weakly tidal littoral zone on Kerteminde Fjord, Denmark. Mar Ecol Prog Ser 122: $165-172$

> Addison JT, Lovewell SRJ (1991) Size composition and pot selectivity in the lobster (Homarus gammarus [L.]) and crab (Cancer pagurus L.) fisheries on the east coast of England. ICES J Mar Sci 48:79-90

Aguzzi J, Sarda F, Allué R (2004) Seasonal dynamics in Nephrops norvegicus (Decapoda: Nephropidae) catches off the Catalan coasts (Western Mediterranean). Fish Res 69:293-300

Aguzzi J, Cuesta JA, Librero M, Toja J (2005) Daily and seasonal feeding rhythmicity of Palaemonetes varians (Leach 1814) from southwestern Europe. Mar Biol 148:141-147
Atkinson RJA, Parsons AJ (1973) Seasonal patterns of migration and locomotor rhythmicity in populations of Carcinus. Neth J Sea Res 7:81-93

> Crisp DJ (1964) The effects of the severe winter of 1962-63 on marine life in Britain. J Anim Ecol 33:165-210

Crothers JH (1968) The biology of the shore crab, Carcinus maenas (L.) 2. The life of the adult crab. Field Stud 2: $579-614$

Elner RW (1980) The influence of temperature, sex and chela size in the foraging strategy of the shore crab, Carcinus maenas. Mar Behav Physiol 7:15-24

Elner RW, Hughes RN (1978) Energy maximization in the diet of the shore crab, Carcinus maenas. J Anim Ecol 47: $103-116$

Gascoigne JC, Beadman HA, Saurel C, Kaiser MJ (2005) Density dependence, spatial scale and patterning in sessile biota. Oecologia 145:371-381

Gwinner E (1996) Circadian and circannual programmes in avian migration. J Exp Biol 199:39-48

> Hunter E, Naylor E (1993) Intertidal migration by the shore crab Carcinus maenas. Mar Ecol Prog Ser 101:131-138

> Jensen GC, McDonald PS, Armstrong DA (2002) East meets west: competitive interactions between green crab Carcinus maenas, and native and introduced shore crab Hemigrapsus spp. Mar Ecol Prog Ser 225:251-262

Jubb CA, Hughes RN, Rheinallt TA (1983) Behavioural mechanisms of size-selection by crabs, Carcinus maenas (L.) feeding on mussels, Mytilus edulis L. J Exp Mar Biol Ecol 66:81-87

Katsanevakis S, Stephanopoulou S, Miliou H, MoraitouApostolopoulou M, Verriopoulos G (2005a) Oxygen consumption and ammonia excretion of Octopus vulgaris (Cephalopoda) in relation to body mass and temperature. Mar Biol 146:725-732

Katsanevakis S, Protopapas N, Miliou H, Verriopoulos G (2005b) Effect of temperature on specific dynamic action in the common octopus, Octopus vulgaris (Cephalopoda). Mar Biol 146:733-738

Kenagy GJ (1981) Effects of day-length, temperature, and endogenous control on annual rhythms of reproduction and hibernation in chipmunks (Eutamias ssp. [sic]). J Comp Physiol 141:369-378

> Last KS, Olive PJW (2004) Interaction between photoperiod and an endogenous seasonal factor in influencing the diel locomotor activity of the benthic polychaete Nereis virens Sars. Biol Bull 206:103-112

> Lynch BR, Rochette R (2009) Spatial overlap and interaction between sub-adult American lobsters, Homarus americanus, and the invasive European green crab Carcinus maenas. J Exp Mar Biol Ecol 369:127-135

Maceina MJ, Rider SJ, Lowery DR (1993) Use of a catchdepletion method to estimate population density at age-0 largemouth bass in submersed vegetation. N Am J Fish Manag 13:847-851

> Maunder MN, Sibert JR, Fonteneau A (2006) Interpreting catch per unit effort data to assess the status of individual stocks and communities. ICES J Mar Sci 63:1373-1385

Miron G, Audet D, Landry T, Moriyasu M (2005) Predation potential of the invasive green crab (Carcinus maenas) and other common predators on commercial bivalve species found on Prince Edward Island. J Shellfish Res 24:579-586

Murray LG (2008) The impact of Carcinus maenas on commercial mussel beds. PhD Thesis, University of Wales, Bangor

Murray LG, Seed R, Jones T (2007) Predicting the impact of Carcinus maenas predation on cultivated Mytilus edulis beds. J Shellfish Res 26:1089-1098 
Naylor E (1958) Tidal and diurnal rhythms of locomotor activity in Carcinus maenas (L.). J Exp Mar Biol Ecol 35:602-610

> Naylor E (1962) Seasonal changes in a population of Carcinus maenas (L.) in the littoral zone. J Anim Ecol 31:601-609

Naylor E (1963) Temperature relationships of the locomotor rhythm of Carcinus. J Exp Biol 40:669-679

Rewitz K, Styrishave B, Depledge MH, Andersen O (2004) Spatial and temporal distribution of shore crabs Carcinus maenas in a small tidal estuary (Looe Estuary, Cornwall, England). J Crustac Biol 24:178-187

Robertson RF, Meagor J, Taylor EW (2002) Specific dynamic action in the shore crab, Carcinus maenas (L.), in relation to acclimation temperature and to the onset of the emersion response. Physiol Biochem Zool 75:350-359

Rossong MA, Williams PJ, Comeau M, Mitchell SC, Apaloo J (2006) Agonistic interactions between the invasive green crab, Carcinus maenas (Linnaeus) and juvenile American lobster, Homarus americanus (Milne Edwards). J Exp Mar Biol Ecol 329:281-288

Sanchez-Salazar ME, Griffiths CL, Seed R (1987) The effect of size and temperature on the predation of cockles Cerastoderma edule (L.) by the shore crab Carcinus maenas (L.). J Exp Mar Biol Ecol 111:181-193

Seed R (1969) The ecology of Mytilus edulis L. (Lamellibranchiata) on exposed rocky shores. II. Growth and mortality. Oecologia 3:317-350

Seed R, Suchanek TH (1992) Population and community ecology of Mytilus edulis. In: Gosling EM (ed) The mussel Mytilus: ecology, physiology, genetics and culture. Elsevier, London, p 87-171

Silverin B, Massa R, Stokkan KA (1993) Photoperiodic adaptation to breeding at different latitudes in great tits. Gen Comp Endocrinol 90:14-22

Styrishave B, Andersen O (2000) Seasonal variations in hepatopancreas fatty acid profiles of 2 colour forms of shore crabs, Carcinus maenas. Mar Biol 137:415-422

Editorial responsibility: Jana Davis,

Annapolis, Maryland, USA
Teschke M, Kawaguchi S, Meyer B (2007) Simulated light regimes affect feeding and metabolism of Antarctic krill, Euphausia superba. Limnol Oceanogr 52:1046-1054

Tweddle JF, Simpson JH, Janzen CD (2005) Physical controls of food supply to benthic filter feeders in the Menai Strait. Mar Ecol Prog Ser 289:79-88

Ungfors A, Hallback H, Nilsson PG (2007) Movement of adult edible crab (Cancer pagurus L.) at the Swedish West Coast by mark-recapture and acoustic tracking. Fish Res 84:345-357

USNO (2007) Complete sun and moon data for one day. Astronomical Applications Department of the U.S. Naval Observatory. Accessed 19 May. http://aa.usno.navy.mil

van der Meeren GI (1994) Sex- and size-dependent mating tactics in a natural population of shore crabs Carcinus maenas. J Anim Ecol 63:307-314

Venema SC, Creutzberg F (1973) Seasonal migration of the swimming crab Macropipus holsatus in an estuarine area controlled by tidal streams. Neth J Sea Res 7:94-102

> Wallace JC (1973) Feeding, starvation and metabolic rate in the shore crab Carcinus maenas. Mar Biol 20:277-281

Walter JF, Hoenig JM, Gedamke T (2007) Correcting for effective area fished in fishery-dependent depletion estimates of abundance and capture efficiency. ICES J Mar Sci 64:1760-1771

Watari Y, Arai T (1997) Effects of photoperiod and aging on locomotor activity rhythms in the onion fly, Delia antiqua. $\mathrm{J}$ Insect Physiol 43:567-576

Welch WR (1968) Changes in the abundance of the green crab, Carcinus maenas (L.), in relation to recent temperature changes. Fish Bull 67:337-345

Williams MJ, Hill BJ (1982) Factors influencing pot catches and population estimates of the portunid crab Scylla serrata. Mar Biol 71:187-192

Wright I, Caputi N, Penn J (2006) Depletion-based population estimates for western rock lobster (Panulirus cygnus) fishery in Western Australia. N Z J Mar Freshw Res 40:107-122

Submitted: August 19, 2008; Accepted: November 12, 2009

Proofs received from author(s): February 9, 2010 